\title{
Surfactant screening to generate strong foam with formation water and crude oil
}

\author{
Muhammad Khan Memon ${ }^{1} \cdot$ Khaled Abdalla Elraies $^{1} \cdot$ Mohammed Idrees Ali Al-Mossawy $^{1}$
}

Received: 21 March 2021 / Accepted: 27 July 2021 / Published online: 5 August 2021

(c) The Author(s) 2021

\begin{abstract}
Most of the available commercial surfactants precipitate due to the hardness of formation water. The study of surfactant generated foam and its stability is very complex due to its multifaceted pattern and common physicochemical properties. This research involved the study of foam generation by using the blended surfactants and their evaluation in terms of enhanced oil recovery (EOR). The objective of this study is to systematic screening of surfactants based on their capability to produce stable foam in the presence of two different categories of crude oil. Surfactant types such as non-ionic, anionic and amphoteric were selected for the experimental study. The foam was generated with crude oil, and the synthetic brine water of 34,107 ppm used as formation water. Surfactant concentration with the both types of crude oil, foam decay, liquid drainage and foam longevity was investigated by measuring the generated foam volume above the liquid level. The surfactant with concentration of $0.6 \mathrm{wt} \% \mathrm{AOS}_{\mathrm{C} 14-16}, 1.2 \mathrm{wt} \% \mathrm{AOS}_{\mathrm{C} 14-16}, 0.6 \mathrm{wt} \% \mathrm{AOS}_{\mathrm{C} 14-16}+0.6 \mathrm{wt} \% \mathrm{TX} 100$ and $0.6 \mathrm{wt} \% \mathrm{AOS}_{\mathrm{C} 14-16}+0.6 \mathrm{wt} \% \mathrm{LMDO}$ resulted in the maximum foam longevity with formation water and two categories of crude oil. The $50 \%$ liquid drainage and foam decay of surfactant solutions with concentration of $0.6 \mathrm{wt} \% \mathrm{AOS}_{\mathrm{C} 14-16}+0.6 \mathrm{wt} \% \mathrm{LMDO}$ and $0.6 \mathrm{wt} \% \mathrm{AOS}_{\mathrm{C} 14-16}+0.6 \mathrm{wt} \% \mathrm{TX} 100$ were noted with the maximum time. The findings of this research demonstrated that the generated foam and its longevity is dependent on the type of surfactant either individual or blended with their concentration. The blend of surfactant solution combines excellent foam properties.
\end{abstract}

Keywords Crude oil $\cdot$ Foam generation $\cdot$ Foam stability $\cdot$ Foam decay $\cdot$ Liquid drainage $\cdot$ Surfactants

\section{Introduction}

The stability of generated foam with crude oil is a major challenge and is considered a significant factor to foam enhanced oil recovery (EOR). The term stability means relatively stable in a kinetic sense. No generated foams are stable thermodynamically. The stability of a generated foam is measured by its half-life or average life time (Sheng et al. 1997). The oil adversely affects the stability of the generated foam. The foam can be weakened or destroyed in the presence of crude oil (Schramm and Novosad 1992; Andrianov et al. 2011). Foam stability in the porous media is a composite function of foam film and rock petro-physical properties. Most of the foam oil interaction characteristics have been

Muhammad Khan Memon

mkmemon@hotmail.com

1 Petroleum Engineering Department, Universiti Teknologi PETRONAS, Bandar Seri Iskandar 32610 Tronoh, Perak Darul Ridzuan, Malaysia performed by using the bulk column tests. In the performed experiments, the height of the foam was calculated as a representative of the surfactant ability to create a stable foam with crude oil (Manlowe and Radke 1990). Foaming properties are generally divided into foamability and foam stability. Foamability refers to how rapidly the foam is generated. In other words, it is the ability to generate bubbles easily. Greater the foamability more stable are the foam films. The foamability of surfactant aqueous solutions can be evaluated by the generated amount of foam. Foam stability is defined as the time that foam will maintain its initial properties as generated. With the generation of foam, surface area of liquid and surface energy are increased. According to the Gibbs principle of minimum free energy, the system always tends to reduce the surface energy level. Low surface tension reduces the energy of the foam system, thus favouring the stability of the foam. Changes in surface tension affect the elasticity of the foam film, which in turn affects the type and the concentration of surfactants (Wei et al. 2018). One of the most important factors in the liquid drainage rate from 
lamella is the difference in the pressure generated inside the lamella and the plateau borders. Liquid drainage, bubble coalescence and disproportionation are three different processes that cause the instability of the foam produced. Drainage is the flow of liquid from a generated foam as a result of gravity and capillary forces. As a consequence of drainage, a foam becomes dryer and bubbles may become distorted that resulted foams conversion from spherical to polyhedral foams. Bubble coalescence is the merging of two bubbles as a result of the rupture of thin films between the bubbles. Larger bubbles appear in the foam, and the number of bubbles decreases. The use of surfactant blend solutions improves the foam stability by adsorbing onto the interfaces, and preventing bubble coalescence through steric effects. Disproportionation is also known as inter bubble gas diffusion and Ostwald ripening. In this process, larger bubbles grow at the expense of smaller bubbles. The smaller bubbles will shrink and eventually disappear. These processes affect the distribution of the liquid and gas phase and therefore change the properties of the foam (Bisperink et al. 1992). The stability of generated foam with crude oil is improved by increasing the hydrophilic chain length of the surfactant that increases its solubilization power of hydrocarbons (Nikolov et al. 1986). Hydrophilic group is polar in nature and soluble in water. Hydrophilic head (the length of the carbon chain) of surfactant is important and represents the lipophilic chain length. Hydrophobic group is non-polar and insoluble in water. Generally, surfactants have lipophilic chain between 8 and 20 carbon atoms. The short chain surfactants are easily soluble in water, and the long chain surfactants are less soluble (Hargreaves and Hargreaves 2003). Increasing the length of hydrophobic group may increase the efficiency of the surfactants (Rosen 2004). Anionic, nonionic and cationic surfactants are commonly used to generate foams. The surfactant concentration affects the stability of the foam. From a molecular point of view, the reduction of foam stability and interfacial tension are controlled by the orientation of the surfactant molecules at the interface. Surface molecules are absorbed at the interface by electrostatic reactions. Its absorption is fast and reversible. As the number of bubbles in the foam increases, the effective viscosity of the gas increases, and the surface fluid is absorbed at a larger contact surface between the two fluids that increasing the thickness of the lamella. Therefore, liquid can drain at a slower rate from the lamella. In addition, it increases the stability of the foam by reducing the capillary forces due to reducing the interfacial tension (Solbakken 2015). Alpha olefin sulfonates (AOS) are a group of anionic surfactants that exhibit high biodegradability and low toxicity. These surfactants are also distinguished by exceptional wetting, dispersing, emulsifying, foaming and stabilizing abilities (Harutyunyan and Harutyunyan 2019). Sodium dodecyl sulphate (SDS) belongs to a group of surfactants called alkyl sulphates. It is an anionic surfactant and used in many cleaning products. The performance of this detergent can be affected significantly by its purity. SDS is easily precipitable in the presence of potassium salts. Internal olefin sulfonates (IOS) are a group of anionic surfactants that are widely used in EOR due to their remarkable ability to withstand harsh reservoir conditions of temperature and salinity. IOS surfactants have several valuable properties when used in EOR. Alkyl aryl sulfonates (AAS) are the most common type of the sulfonate surfactants. In sulfonate surfactants, the sulphur atom is directly attached to the carbon atom of the alkyl group. Therefore, the sulfonate surfactant molecules have a high stability against the hydrolysis reaction. Recently, AAS surfactants have been used commonly in EOR processes (Tackie-Otoo et al. 2020; Machale et al. 2020). Generally, it is preferred to use these anionic surfactants on sandstones and clays due to their low adsorption on their surfaces. They are also stable at high temperatures and can be modified according to the reservoir conditions (Machale et al. 2019). Sodium alpha olefin sulfonate (STEPANTAN AS12 46) is an anionic surfactant and high temperature foamer with high flash foam. Flash foam refers to the foaming behaviour of a liquid during foaming. Good flash foam means that a lot of foam is generated quickly. It is an excellent foamer in fresh, medium, soft and hard waters. Ammonium lauryl sulphate or alkyl ethoxy sulphate (STEOL CS-460) is anionic surfactant with an excellent foam properties and foam stability. It can be used as a secondary surfactant, compatible with anionic and non-ionic surfactants. Ammonium alcohol ether sulphate (STEPSOL CA-406H) or alcohol ethoxy sulphate (AES) is anionic surfactant that provides excellent foam properties and foam stability (Company and Surfactants [online], 2021). Non-ionic surfactants are good for salinity tolerance but have low performance and foam stability. These types of surfactant contain an ethylene oxide (EO) group in the form of ethoxylates. They are soluble in both organic solvents and water. Octylphenol ethylene oxide (Triton TX-100) is a non-ionic surfactant. It has a hydrophilic polyethylene oxide chain and an aromatic hydrocarbon lipophilic or hydrophobic group. Amphoteric surfactants contain positive and negative charge groups on their hydrophilic heads. The central property of amphoteric surfactants is that their ionic form can be determined by the $\mathrm{pH}$ of the solution in which they are dissolved. In other words, they turn into positively charged molecules in the acidic state and are similar to cationic surfactants, while under alkaline conditions they obtain a negative charge and are similar to anionic surfactants. Therefore, the unique behaviour of changing the charge with $\mathrm{pH}$ affects the properties of the solution including surface tension, wettability, foaming and detergency. The anionic surfactants contain only the negatively charged groups in the hydrophilic heads. These types of surfactants are one of the most widely used in various applications and 
research fields (Kumar and Mandal 2017; Guanhua et al. 2019). Amphoteric surfactants contain two groups; nonionic-anionic and nonionic-cationic or anionic-cationic (Lake 1989). These surfactants are expensive and temperature/brine salinity tolerant. Lauramidopropyl amine oxide (LMDO) is an example. Amine oxide can be used as co solvent with primary surfactants as mixed micelle for EOR. Amine oxides are salt tolerant that reduces the IFT and can build viscosity. It can be used with anionic, non-ionic and cationic surfactants. The foam by the surfactant solutions either individual or mixed can be produced by shaking vigorously in the screw capped glass. As soon as the height of the foam produced in the glass, time is noted to evaluate the foamability and foam stability (Sie and Nguyen 2020). Agneta et al. (2019) focussed on foam efficiency by mixed surfactant solutions in the presence of high salinity of $461.280 \mathrm{~g}$ in $1538.73 \mathrm{~mL}$ of water at $25^{\circ} \mathrm{C}$. In their research study, anionic surfactant sodium dodecyl sulphate, cationic surfactant hexadecyltrimethyl ammonium bromide and nonionic surfactant TX-100 were used. They concluded that the synergistic mixed surfactant system in the right proportions exhibited better foamability and stability than the individual surfactants (Agneta et al. 2019). Razavi et al. (2020) performed the experiments on foam stability in the presence and absence of crude oil at $25{ }^{\circ} \mathrm{C}$ and atmospheric pressure. They used four different categories of crude oil to generate the foam with the solution of blended and individual surfactants. The findings of their research showed that surfactant type significantly affects the foam stability. Further, blended solution of surfactant generated more stable foam as compared to the individual surfactant (Razavi et al. 2020).
Yao et al. (2020) studied interfacial properties and the mechanism of strong foam generation by adding dispersed particle gel (DPG). The foaming agent tetradecyl hydroxyl sulfobetaine was used in their study. They investigated the interfacial tension, the foam half-life time, liquid drainage through laboratory experiments performed at room temperature and atmospheric pressure (Yao et al. 2020).

\section{Foam flow types in porous media}

Foam is the diffusion of gas in a continuous liquid phase, which can be a small fraction of the foam by volume. The gas phase is irregularly ordered in the gas bubbles (Exerowa and Kruglyakov 1998; Weaire and Hutzler 1999). The bubbles are connected by thin liquid films called foam films (lamellae). Figure 1 shows different foam flow types in porous media. Three types of foams are generated in the porous media. Each type of foam is defined as follows.

\section{Pre-existing foams}

Pre-existing foams are destabilized and destroyed. Foam is destabilized in a high capillary pressure environment, in a strongly oil-wet formation, and in a medium with high oil saturation are the examples of pre-existing foam.

\section{Strong foam}

A foam contains several lamellae with the size of small bubbles. This significantly reduces gas mobility because of the finely textured foam. This foam is formed because of high
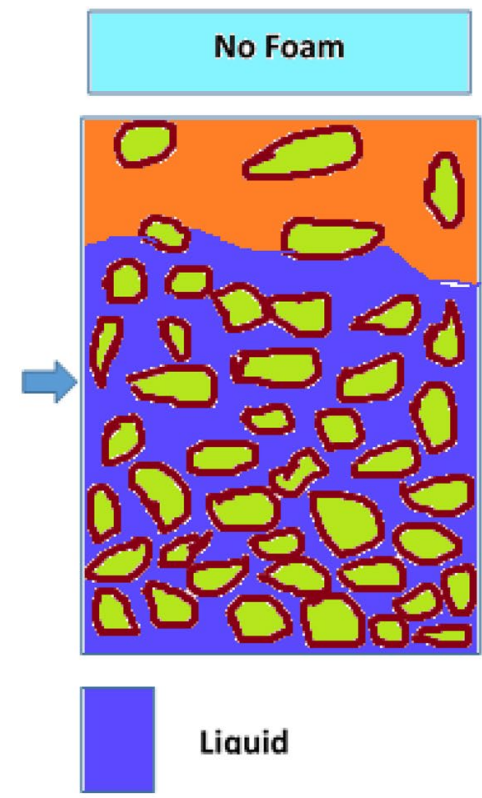

Liquid

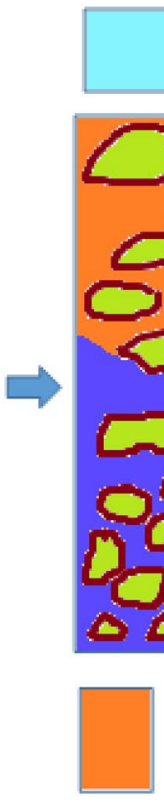

\section{Weak Foam}

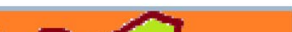

302

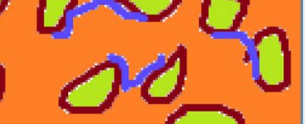

Gas

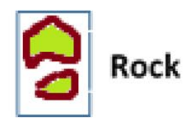

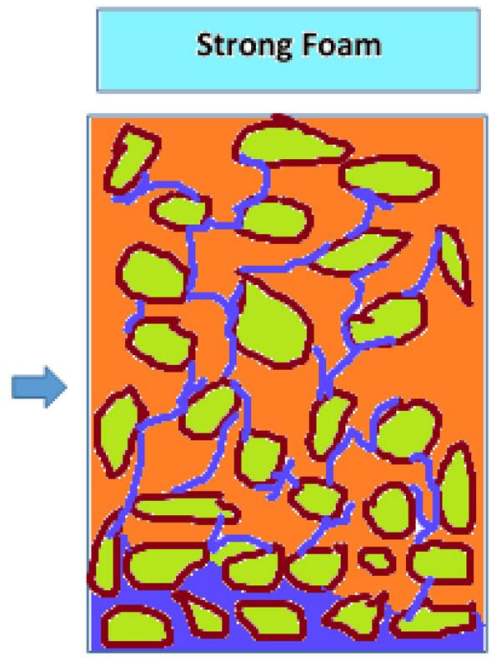

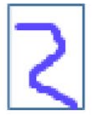

Lamellae

Fig. 1 The flow of different types of foam in porous media

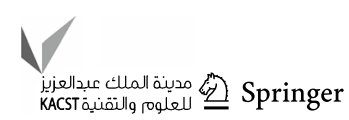


injection velocity. The presence of numerous foam films form very fine textured foam is referred to as strong foam. Strong foam may increase the effective foam viscosity or decrease the relative gas permeability up to several orders of magnitude, exhibiting a dramatic increase in pressure gradient or reduction in water saturation.

\section{Weak foam}

If the surfactant generates a small number of lamellae with large size of bubbles is known as weak foam. The generated foam is coarsely textured and resulted in a moderate reduction in the gas mobility. Weak foam is formed because of low injection velocity. This type of foam can be formed by exhibiting a moderate increase in effective foam viscosity, typically by less than a few orders of magnitude leading to a moderate increase in pressure gradient or reduction in water saturation. The transition foam is formed by a gradual increase in the injection velocity from the weak foam to the strong foam. The alteration from weak foam to the strong foam is called foam generation. Once the generation of foam began, the mobility of the gas phase decreased and the pressure gradient increased (Lopera Castro et al. 2009).

According to the published literature, surfactants with low carbon content (less than 10) are not suitable for use as a foaming agent. Surfactants with long carbon chains are more prone to intermolecular interaction, which results in lower solubility in water solution and poor film elasticity (Farzaneh and Sohrabi 2015). This study provides more visions into the potential performance of optimum surfactants with formation water and two categories of crude oil. The concentration of individual and blended surfactant solutions was tested to evaluate their performance in generating stable foam for EOR applications. Further, an investigation has been made a foam longevity, foam half-life time and liquid drainage of single and blended surfactant solutions. The synergistic effect of the blended surfactant solutions in order to increase the foam stability is also studied in this work.

\section{Materials}

\section{Surfactants}

The list of the commercial surfactants used in the experiments for screening the surfactant is shown in the Table 1 .

\section{Crude oil}

Two categories of crude oil were collected from offshore oil fields of Malaysia. Table 2 shows the crude oil properties.

\section{Brine water}

The synthetic brine water was prepared in the laboratory. Table 3 shows the composition of brine water used as formation water.

Table 1 Selected surfactants for the laboratory evaluation

\begin{tabular}{|c|c|c|c|c|c|}
\hline S. no & Chemical name & Chemical description & Type & Purity (\%) & Boiling point $\left({ }^{\circ} \mathrm{C}\right)$ \\
\hline 1 & BIO-TERGE AS-40 AOS $_{\mathrm{C} 14-16}$ & Alpha Olefin Sulfonate (AOS) & Anionic & 39 & $>100$ \\
\hline 2 & STEPSOL CA-406H & Ammonium Alcohol Ether Sulphate & Anionic & 60 & $>94$ \\
\hline 3 & STEPANTAN AS-12 46 & Sodium Alpha Olefin Sulfonate & Anionic & 46 & 100 \\
\hline 4 & ENORDET $0332\left(\mathrm{IOS}_{\mathrm{C} 15-18}\right)$ & Internal Olephin Sulfonate (IOS) & Anionic & 33.4 & $>200$ \\
\hline 5 & SDS & Sodium Dodecyl Sulphate (Solid) & Anionic & 100 & $>100$ \\
\hline 6 & Triton TX-100 & Octylphenol Ethylene Oxide & Non-ionic & 100 & 270 \\
\hline 7 & ENORDET J771 (AAS) & Alcohol Aloxy Sulphate/Alkyl Ether Sulphate & Additive & 26.2 & 60 \\
\hline 8 & STEOL CS-460 & Sodium Lauryl Sulphate, 3MolesEO & Secondary Surfactant & 59 & 87.8 \\
\hline 9 & AMMONYX LMDO & Lauryl Amido Propyl Amine oxide & Amphoteric & 33 & $>100$ \\
\hline
\end{tabular}

Table 2 Waxy and normal crude oil properties

\begin{tabular}{|c|c|c|c|c|c|c|c|c|}
\hline \multirow[t]{2}{*}{ Oil type } & \multirow{2}{*}{$\begin{array}{l}\text { Density }(\mathrm{g} / \\
\left.\mathrm{cm}^{3}\right) 20^{\circ} \mathrm{C}\end{array}$} & \multirow{2}{*}{$\begin{array}{l}\text { Viscosity } \\
\text { (cp) } 20{ }^{\circ} \mathrm{C}\end{array}$} & \multirow[t]{2}{*}{${ }^{\circ} \mathrm{API}$} & \multirow[t]{2}{*}{ Wax content $(\%)$} & \multicolumn{4}{|l|}{ SARA analysis } \\
\hline & & & & & Saturates (wt $\%)$ & $\begin{array}{l}\text { Aromatics } \\
\text { (wt } \%)\end{array}$ & Resins (wt $\%$ ) & $\begin{array}{l}\text { Asphaltenes } \\
\text { (wt } \%)\end{array}$ \\
\hline Normal oil & 0.802 & 6.89 & 41.25 & 11 & 83.01 & 15 & 1.73 & 0.12 \\
\hline Waxy oil & 0.852 & 8.4 & 37.7 & 26.7 & 82.15 & 15.4 & 2.26 & 0.18 \\
\hline
\end{tabular}


Table 3 Brine water/formation water composition

\begin{tabular}{ll}
\hline Salt & $(\mathrm{mg} / \mathrm{L})$ \\
\hline Sodium & 10,603 \\
Chloride & 18,807 \\
Calcium & 354 \\
Magnesium & 1219 \\
Potassium & 325 \\
Bicarbonate & 163 \\
Sulphate & 2636 \\
Total salinity $(\mathrm{ppm})$ & 34,107 \\
\hline
\end{tabular}

\section{Methodology}

\section{IFT measurement}

A data physics S20 spinning drop tensiometer was used for IFT measurements. The interfacial tension (IFT) test between surfactant, brine water and crude oil was performed. The same procedure for IFT measurement was used in this work as measured IFT values in the previous published work (Memon et al. 2020).

\section{Foam stability test}

Foam stability test provides ideas of possible interaction between crude oil and surfactant solutions. Further, experimental data provide valuable basic information on generated foam and its stability by different surfactant concentration, oil and surfactant type. The aim of this test is to check whether or not the surfactants can produce a stable foam. This test provides a preliminary and rapid assessment of the generated foam ability of surfactants. Experiments were carried out at room temperature and atmospheric pressure. First of all, the stability of the generated foam was carried out using the different concentrations of individual and blend of surfactant solutions with formation water. Figure 2 shows a schematic diagram for the process of foam generation with formation water and with crude oil. Surfactant solution of $20 \mathrm{~mL}$ was placed in a graduated cylinder. Stirrer was set at a fixed speed of $3420 \mathrm{rpm}$ for $5 \mathrm{~min}$ to generate a large volume of the foam layer. The cylinder was covered with the aluminium foil at the top to prevent the impact of environmental disturbances. After discontinuing the process of foam generation, the generated foam volume at top of the liquid level with respect to time was noted. When generated foam at the initial stage reached half of its initial volume, time was noted. The time noted at the initial foam volume and the time noted when reached its half foam volume are used to investigate the stability of the foam. The large value of the half-life time of the generated foam is consistent with more stable foam (Duan et al. 2014). The same process was repeated with the addition of $2 \mathrm{~mL}$ of crude oil along with

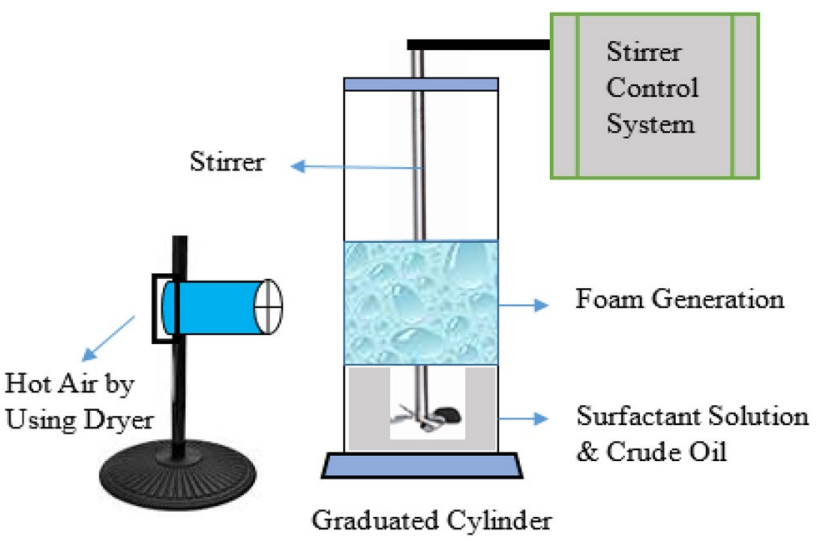

Fig. 2 Schematic diagram of foam generation

the $20 \mathrm{~mL}$ of surfactant solutions. Dryer was used at $50{ }^{\circ} \mathrm{C}$ when generating foam with waxy oil. The foam stability was assessed from the plots of the foam height versus time. The crude oil containing surfactant was measured with the following equation (Llave and Olsen 1994).

Total height of liquid $=$ Emulsion phase + Liquid phase

\section{Results and discussion}

\section{Interfacial tension (IFT)}

The IFT between formation water and waxy oil was resulted as $12 \mathrm{mN} / \mathrm{m}$, while the IFT between formation water and normal oil was resulted as $9.6 \mathrm{mN} / \mathrm{m}$. Table 4 shows the IFT result of the tested surfactant solutions with different concentrations.

Table 4 Interfacial tension by spinning drop tensiometer

\begin{tabular}{lll}
\hline Surfactant solution & $\begin{array}{l}\text { IFT with normal } \\
\text { crude oil }(\mathrm{mN} / \mathrm{m})\end{array}$ & $\begin{array}{l}\text { IFT with waxy } \\
\text { crude oil }(\mathrm{mN} / \mathrm{m})\end{array}$ \\
\hline $0.6 \% \mathrm{AOS}_{\mathrm{C} 14-16}$ & 1.10 & 0.94 \\
$1.2 \% \mathrm{AOS}_{\mathrm{C} 14-16}$ & 0.97 & 0.89 \\
$0.4 \% \mathrm{IOS}_{\mathrm{C} 15-18}$ & 0.14 & 0.134 \\
$0.2 \% \mathrm{AOS}_{\mathrm{C} 14-16}+0.2 \% \mathrm{TX}-100$ & 0.89 & 0.92 \\
$0.6 \% \mathrm{AOS}_{\mathrm{C} 14-16}+0.6 \% \mathrm{TX}-100$ & 0.82 & 0.88 \\
$0.6 \% \mathrm{AOS}_{\mathrm{C} 14-16}+0.6 \% \mathrm{CS} 460$ & 1.45 & 1.32 \\
$0.6 \% \mathrm{AOS}_{\mathrm{C} 14-16}+0.6 \% \mathrm{CA}-$ & 1.96 & 1.85 \\
$406 \mathrm{H}$ & & \\
$0.6 \% \mathrm{AOS}$ & & 1.24 \\
$0.2 \% \mathrm{SDS}+0.2 \% \mathrm{TX}-100$ & 1.42 & 1.50 \\
$0.4 \% \mathrm{SDS}+0.4 \% \mathrm{AAS}$ & 1.435 & 1.15 \\
\hline
\end{tabular}




\section{Foam stability and longevity}

Preliminary foam stability test was performed with synthetic brine (formation water) and two types of crude oil. The stability of the generated foam was investigated by observing the changes in the height of the foam produced in the graduated cylinder over time. As discussed in the methodology section of this paper, the height of the foam was calculated from the top of the generated foam to the amount of liquid level in the graduated cylinder. Figure 3 shows foam stability and longevity with formation water no crude oil and with both types of crude oil (waxy and normal oil) by surfactant AOS and AOS blended surfactant solutions. Individual surfactant $0.6 \% \mathrm{AOS}_{\mathrm{C} 14-16}$ and $1.2 \% \mathrm{AOS}_{\mathrm{C} 14-16}$ have generated additional stable foam with crude oil and aqueous phase as compared to its blend with non-ionic surfactant $0.2 \% \mathrm{AOS}_{\mathrm{C} 14-16}+0.2 \% \mathrm{TX}-100$. Surfactant blend $0.6 \% \mathrm{AOS}_{\mathrm{C} 14-16}+0.6 \% \mathrm{CS} 460$ generated foam $60 \mathrm{~mL}$ without crude oil and $45 \mathrm{~mL}$ with both types of crude oil at the initial time. A small interaction with the crude oil was observed in this surfactant mixture solution.

Figure 4 shows surfactant blend with concentration of $0.6 \% \mathrm{AOS}_{\mathrm{C} 14-16}+0.6 \% \mathrm{CA} 406 \mathrm{H}$ and $0.6 \% \mathrm{AOS}_{\mathrm{C} 14-16}+0.6 \% \mathrm{LMDO}$ generated the foam volume larger than individual surfactant with concentration of $0.6 \% \mathrm{AOS}_{\mathrm{C} 14-16}, 1.2 \% \mathrm{AOS}_{\mathrm{C} 14-16}$ and other tested surfactants. Another surfactant blend with concentration of $0.6 \% \mathrm{AOS}_{\mathrm{C} 14-16}+0.6 \% \mathrm{TX}-100$ generated foam volume lower than the surfactant blend with concentration of $0.6 \% \mathrm{AOS}_{\mathrm{C} 14-16}+0.6 \% \mathrm{CA} 406 \mathrm{H}$ and
$0.6 \% \mathrm{AOS}_{\mathrm{C} 14-16}+0.6 \% \mathrm{LMDO}$ but more than individual surfactant with concentration of $0.6 \% \mathrm{AOS}_{\mathrm{C} 14-16}$ and $1.2 \% \mathrm{AOS}$. These blended surfactant solutions produced stable foam with both types of crude oil and without crude oil. As Rosen (2004) has proved in their work, the stability of foam increased with concentration of surfactant blend solutions.

The generated foam with crude oil by the surfactant blend solution of $0.6 \% \mathrm{AOS}_{\mathrm{C} 14-16}+0.6 \% \mathrm{CA} 406 \mathrm{H}$ collapsed due to its high value of IFT as compared to the other tested surfactants. This type of surfactant blend generated large oil droplets and collapsed due to the steric effects (this interaction appears when chain molecules attached at some point to a surface, dangle out into the solution where they are mobile due to Brownian motion), in which lamellae become thinner and foam becomes more fragile. The average oil droplet becomes larger and breaks the foam due to the limited elasticity of the plateau border. When the surface is subjected to liquid film expansion, the local surface concentration decreases with increasing surface area and the film becomes thinner. The low concentration of surfactant leads to high surface tension. High concentration of surfactant causes reduction of the surface in order to maintain the low energy. This surface reduction induces liquid flow in the film from the low tension region to the higher tension region. Finally, this liquid flow provides the resistance against the thinning of liquid film. Surfactant blend with the concentration of $0.6 \% \mathrm{AOS}_{\mathrm{C} 14-16}+0.6 \% \mathrm{TX}-100$ generated foam with small oil droplets due to its low IFT. Oil droplets have little impact on the foam stability. Figure 5 shows foam lamellae and stable bubbles in small and large size produced
Fig. 3 Stability and longevity of foams created with surfactant solutions using formation water and two categories of crude oil

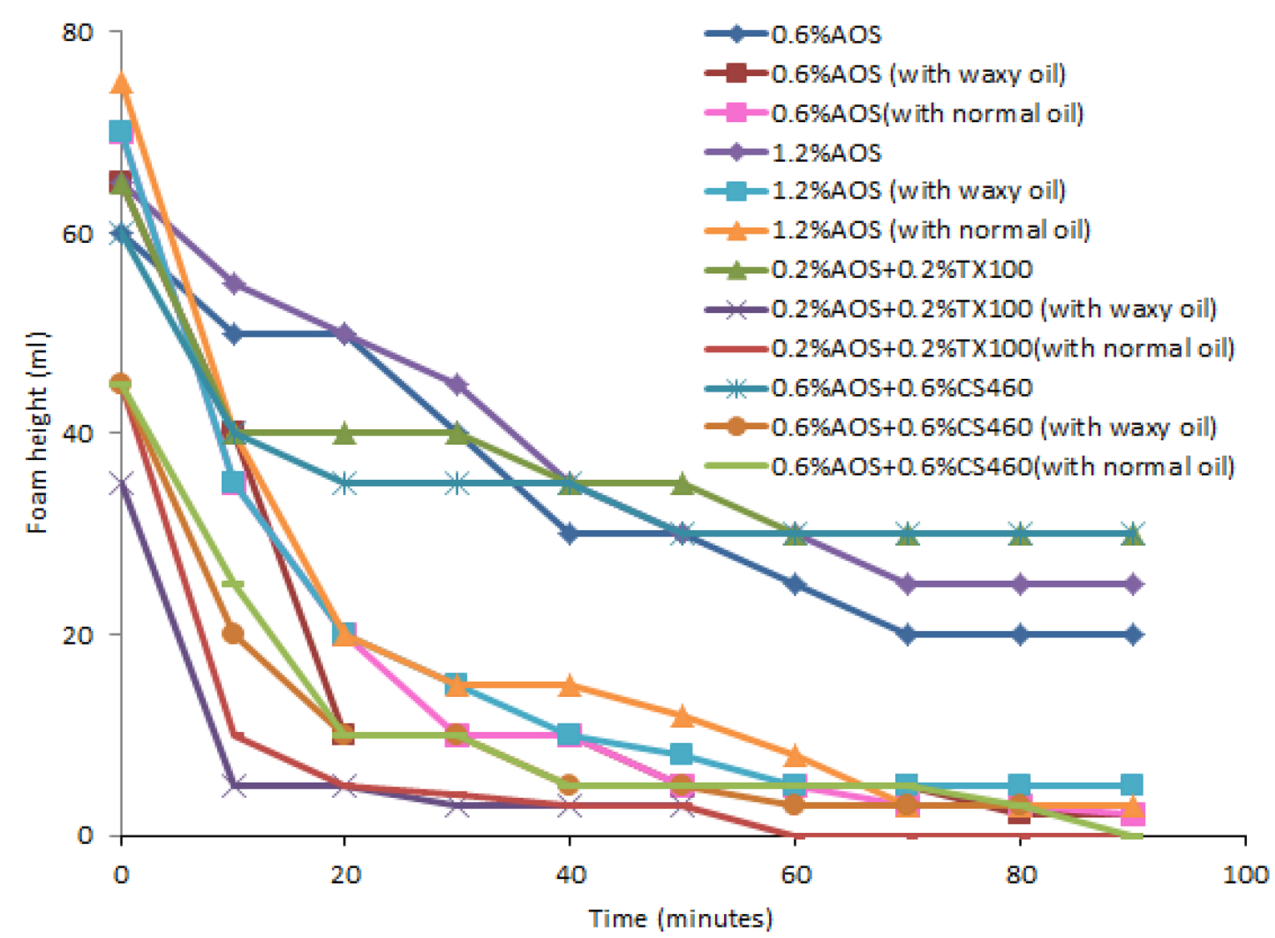


Fig. 4 Stability and longevity of foams created with mixed surfactant solutions using formation water and two categories of crude oil

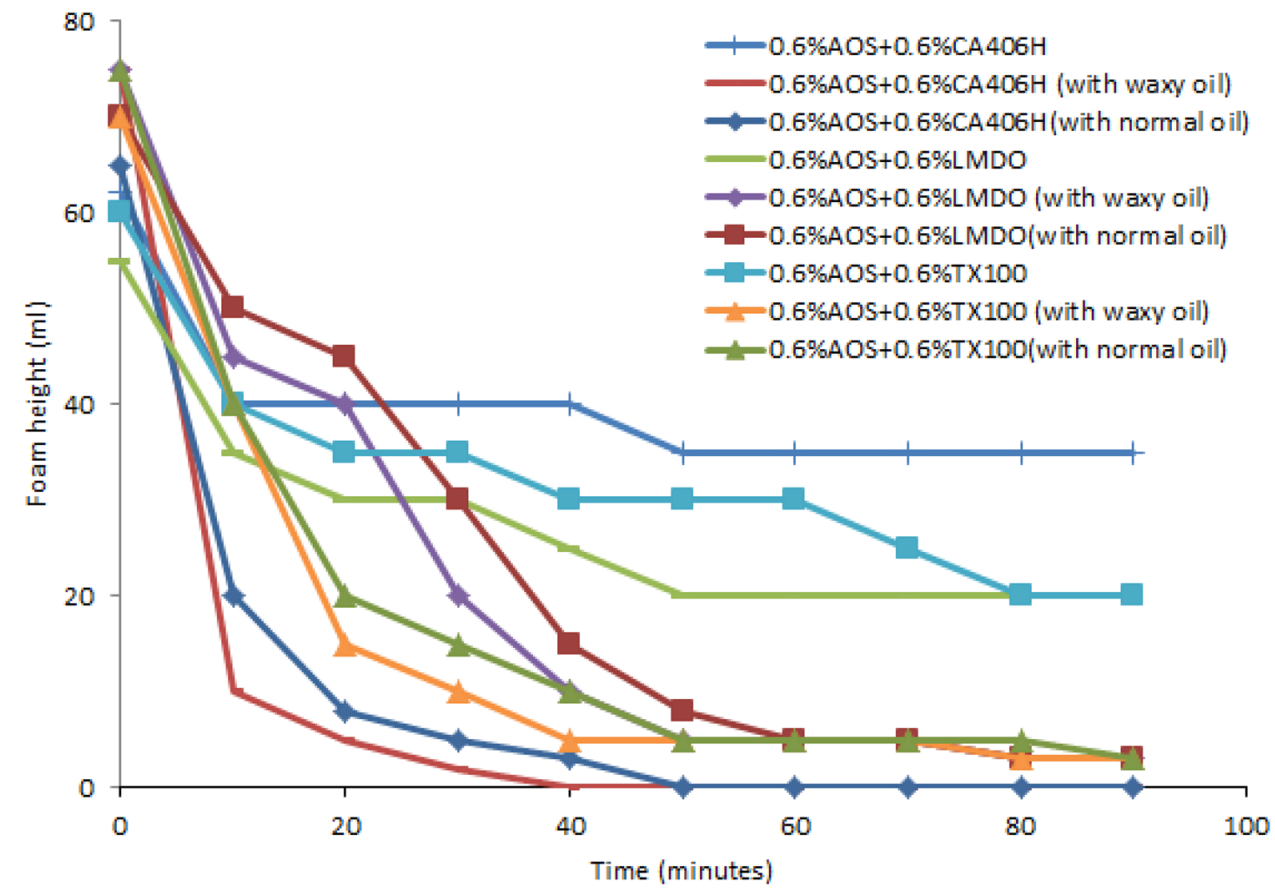

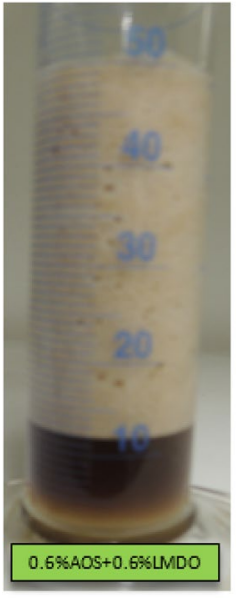

A

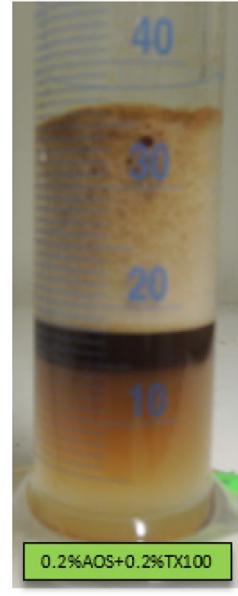

B

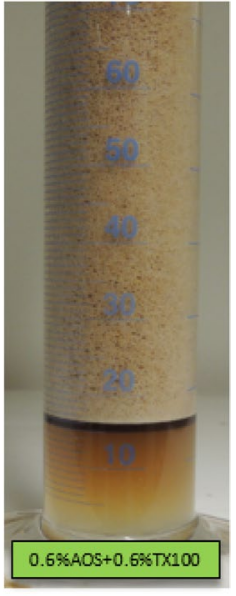

$\mathrm{C}$

Fig. 6 Foam contact with crude oil, generated smaller size of bubbles in the presence of formation water and crude oil. A Blended surfactant $0.6 \% \mathrm{AOS}_{\mathrm{C} 14-16}+0.6 \% \mathrm{LMDO}$. B Blended surfactant $0.2 \% \mathrm{AOS}_{\mathrm{C} 14-16}+0.2 \% \mathrm{TX} 100$. $\mathbf{C}$ Blended surfactant 0 . $6 \% \mathrm{AOS}_{\mathrm{C} 14-16}+0.6 \% \mathrm{TX} 100$

with formation water by the surfactant with concentration of $0.6 \% \mathrm{AOS}_{\mathrm{C} 14-16}$. Bubbles form because of the considerable reduction in the surface tension. The bubbles imposed very high repulsive forces on each other, causing the bubble to deform over a longer period of time due to the high thickness of the liquid film. Initially, the bubbles did not coalesce, maintaining their original size. However, over time, as the bubbles were closer, the bubble coalescence mechanism was dominant, and the bubbles became larger. Figure 6 shows the development of different foams over time. The shape,

size of bubbles and generated foam volume with crude oil were obtained by the different concentrations of surfactant solutions. The stirrer speed accelerates the expansion and disappearance of the foam, and the result is a reduction in the time required for deformation. During the process, the survival time of large size bubbles is short, but the selected fixed stirring speed has less effect on small size bubbles as noted in the generated foam. In the blended surfactant solution, the bubble size becomes smaller and more regular. 
The smaller the size of foam bubbles, the larger is the foam stability. During the individual/single surfactant, the size of the bubbles is larger. Therefore, the disjoining pressure increases and the Ostwald ripening mechanism becomes less effective. The thickness of the liquid film and the generated foam depend mainly on the foam stabilizer and stabilization method. When the concentration of surfactant is high, the system produces more relatively small bubbles. Compared to larger bubbles, which are more likely to collapse, the smaller bubbles are more stable. Under normal conditions, the stability of the bubbles is poor and the collapse speed is fast. Therefore, it is difficult to obtain a specific bubble size by experiments on the thickness of the liquid film and the height of the generated foam. The density and viscosity of the liquid phase have relatively little effect on foam stability. Due to the adsorption of surfactants in the bubbles and the electrostatic repulsion between the bubbles, small size bubbles are more easily absorbed by the large size bubbles, and the liquid phase in the small size bubbles will be dispersed into other bubble systems, increasing the thickness of the liquid film. However, compared with large size bubbles, for which the liquid film cannot be completely filled, so for small-sized bubbles, the liquid phase will fill more evenly. Therefore, the smaller sized bubbles are more stable (Osei-Bonsu et al. 2015; Huang et al. 2021). The blended surfactant solutions of $0.6 \% \mathrm{AOS}_{\mathrm{C} 14-16}+0.6 \% \mathrm{TX}-100$ and $0.6 \% \mathrm{AOS}_{\mathrm{C} 14-16}+0.6 \% \mathrm{LMDO}$ produced more compact bubbles of smaller size. The initial foam height was noted as $70 \mathrm{~mL}$, and slowly foam height was decreased due to the bubbles collapsed and was noted $15 \mathrm{~mL}$ after $40 \mathrm{~min}$ in the both types of crude oil.
Figure 7 shows foam stability and longevity with brine water, waxy and normal crude oil by surfactant SDS blend and surfactant $\operatorname{IOS}_{\mathrm{C} 15-18}$. Foam was generated by the surfactant blend with concentration of $0.2 \% \mathrm{SDS}+0.2 \% \mathrm{TX}-100$ at the initial time with waxy oil as $40 \mathrm{~mL}$, normal oil $42 \mathrm{~mL}$ and with formation water $70 \mathrm{~mL}$, respectively. Stability was increased due to the addition of additives (AAS) with anionic surfactant (SDS). The foam volume by surfactant blend $0.4 \% \mathrm{SDS}+0.4 \%$ AAS was noted at the initial time as $75 \mathrm{~mL}$ without crude oil, $70 \mathrm{~mL}$ with waxy crude oil and $65 \mathrm{~mL}$ with normal crude oil. Weak foam was generated by surfactant $0.4 \% \mathrm{IOS}_{\mathrm{C} 15-18}$ with waxy and normal crude oil. This type of surfactant showed lowest IFT values as compared to all tested surfactants but generated foam showed weak interaction with both types of waxy and normal oil. As discussed in the introduction section of this paper, weak foam produces a small number of lamellae with larger size of bubbles. The low IFT values of this surfactant concentration do not stabilize the foam because this surfactant concentration does not have the required surface power or the required approach rate to equilibrium after surface expansion or contraction. Surfactant that produced foam with a high initial volume is considered to have a good foamability and those which produces foam with a low initial volume are considered to have a weak foamability.

\section{Initial foam volume generated in waxy and normal oil}

Figure 8 shows the height of the foam, which is generated by different surfactant concentration with formation water,
Fig. 7 Generated foam stability and longevity with brine water, waxy and normal crude oil by surfactant SDS blend and surfactant $\operatorname{IOS}_{\mathrm{C} 15-18}$

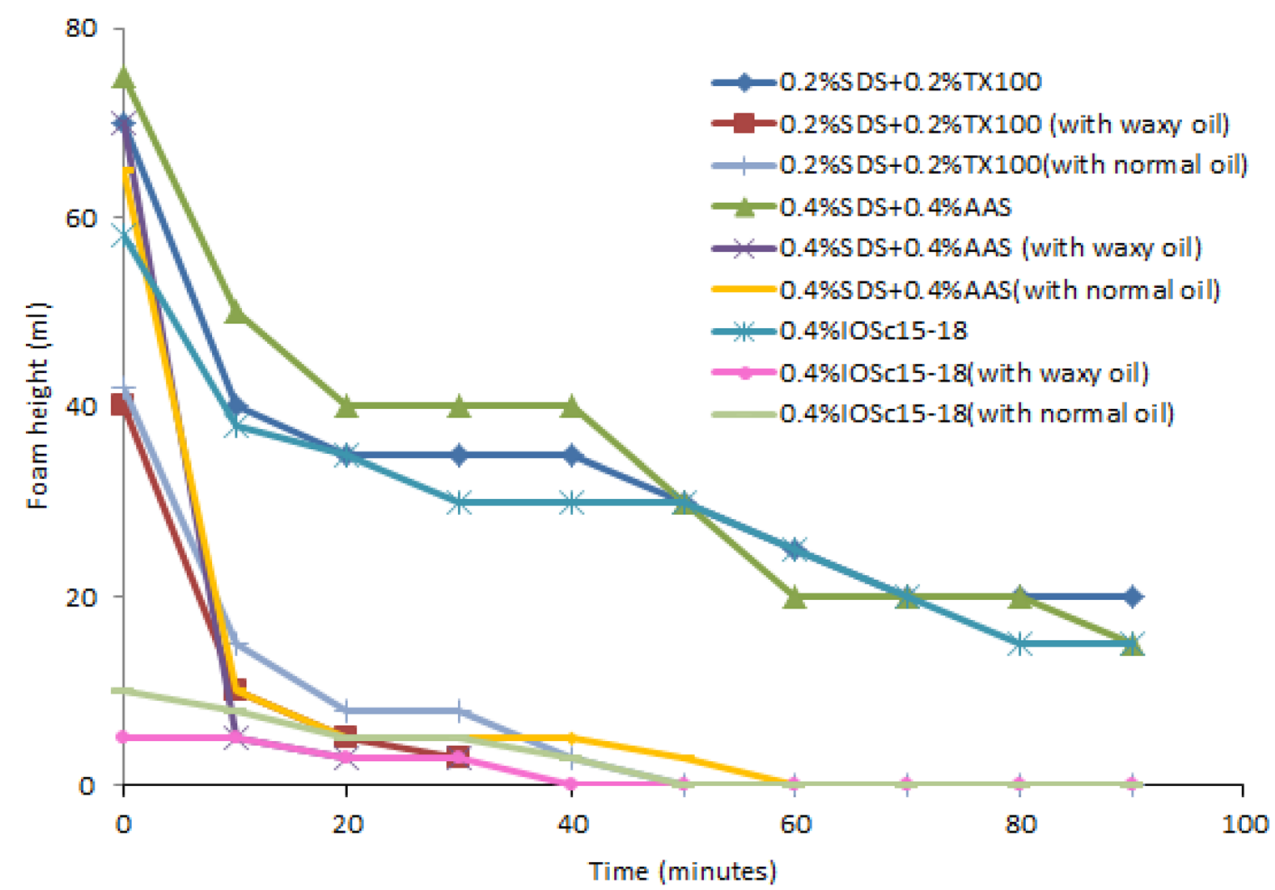


Fig. 8 Initial volume of foam generated with waxy and normal crude oil

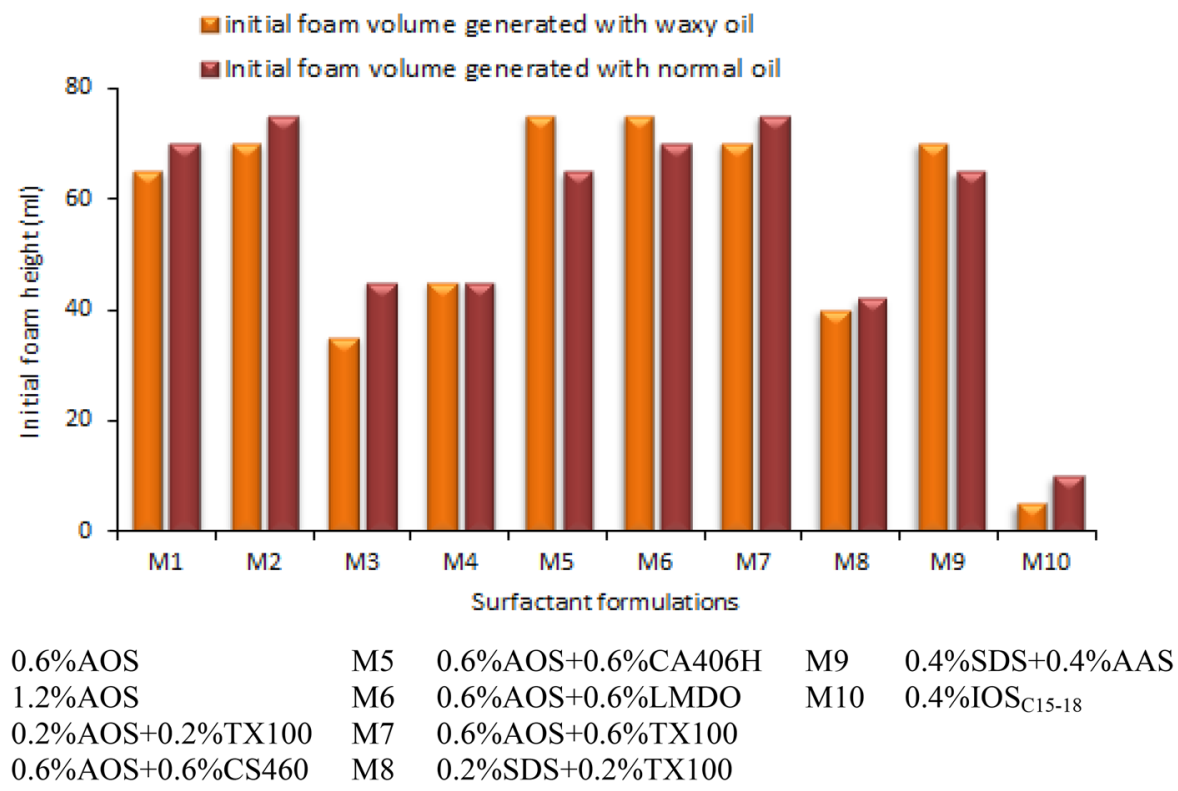

waxy and normal crude oil at the initial time. The blended surfactant with concentrations of $0.2 \% \mathrm{SDS}+0.2 \% \mathrm{TX} 100$ and $0.2 \% \mathrm{AOS}_{\mathrm{C} 14-16}+0.2 \% \mathrm{TX} 100$ generated low foam height due to its low concentration in the both types of oil. Single surfactant with concentration of $0.6 \% \mathrm{AOS}_{\mathrm{C} 14-16}$ and $1.2 \% \mathrm{AOS}_{\mathrm{C} 14-16}$ has generated foam height greater than surfactant with concentration of $0.4 \% \mathrm{IOS}_{\mathrm{C} 15-18}$. Surfactant concentration of $0.4 \% \mathrm{IOS}_{\mathrm{C} 15-18}$ showed small interaction with both types of crude oil. The foam produced by this type of surfactant was initially weak. Surfactant blend with concentration of $0.4 \% \mathrm{SDS}+0.4 \% \mathrm{AAS}$ has generated the same foam height as surfactant with a concentration of $0.6 \% \mathrm{AOS}_{\mathrm{C} 14-16}$. A low interaction with crude oil was observed by $0.6 \% \mathrm{AOS}_{\mathrm{C} 14-16}+0.6 \% \mathrm{CS} 460$. The blended surfactant with concentrations of $0.6 \% \mathrm{AOS}_{\mathrm{C} 14-16}+0.6 \% \mathrm{CA} 406 \mathrm{H}$ and $0.6 \% \mathrm{AOS}_{\mathrm{C} 14-16}+0.6 \% \mathrm{LMDO}$ generated foam height higher than the surfactant concentration of $0.6 \% \mathrm{AOS}_{\mathrm{C} 14-16}$ and other surfactants. Surfactants with concentration of $0.6 \% \mathrm{AOS}_{\mathrm{C} 14-16}+0.6 \% \mathrm{TX} 100$ generated foam height lower than $0.6 \% \mathrm{AOS}_{\mathrm{C} 14-16}+0.6 \% \mathrm{CA} 406 \mathrm{H}$ and surfactant concentration of $0.6 \% \mathrm{AOS}_{\mathrm{C} 14-16}+0.6 \% \mathrm{LMDO}$ but equal to the surfactant concentration of $0.6 \% \mathrm{AOS}_{\mathrm{C} 14-16}$ and mixed surfactant $0.4 \% \mathrm{SDS}+0.4 \% \mathrm{AAS}$. Foam height increases due to the increase in kinetic energy makes it easier for molecules to get free of water bound. It leads that the absorption of surfactant molecules on the interface increases; therefore, the foam height increases.

The impact of oil on the stability of generated foam depends strongly on surfactant type. All surfactants with same concentration were used with normal oil. More foam volume was generated with normal oil by $0.6 \% \mathrm{AOS}_{\mathrm{C} 14-16}+0.6 \% \mathrm{TX} 100$ surfactant as compared to single surfactant $0.6 \% \mathrm{AOS}_{\mathrm{C} 14-16}$. The foam generated by the surfactant concentration of $0.6 \% \mathrm{AOS}_{\mathrm{C} 14-16}+0.6 \% \mathrm{LMDO}$ entered the decay regime soon after discontinuing the process of foam generation in the graduated cylinder. The generated volume of foam declines sharply to a plateau. After a definite time, foam entered a second decay regime, which leads to a limited amount or complete collapse of the foam. The first foam decay was caused mainly due to the gravity drainage. At the end of early decay regime, only a small amount of liquid remained in the foam for both oil types. The role of bubble coalescence was dominant during the second foam decay. The concept of foam decay has been considered as the transfer of surfactant molecules from the gas water interface to the oil water interface, which weakens the film strength of the foam and reduces the Marangoni effect that reduces the performance of the foam (Pu et al. 2017). The bubble collapsing process of foam is mainly affected by the release of energy inside the foam, and high pressure inside the foam. Before the foam breaks, the velocity of the liquid film position fluctuates, and with the increase in time, the amplitude of the velocity fluctuation increases. When the surface energy between the gaseous and liquid phases is less than the kinetic energy inside the gas, the bubble collapses and the energy inside the bubble is released (Huang et al. 2021). The height of generated foam by using different concentrations of surfactant solutions at the initial time are further evaluated in terms of foam half-life time and the liquid drainage time.

\section{Foam half-life time}

The foam half-life time provides the concept of stable foam. When the generated foam volume in the cylinder reaches half of the initial volume, the time was noted

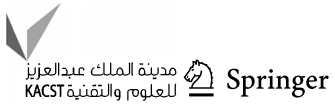


and refers foam half-life time. It correlates with the stability of foam such that an increase in the foam half-life time resulted more stable foam. Figure 9 shows the halflife time of foam by the different concentrations of surfactant solutions with formation water, and both types of crude oil. Without crude oil surfactant concentrations of $0.6 \% \mathrm{AOS}_{\mathrm{C} 14-16}, 1.2 \% \mathrm{AOS}_{\mathrm{C} 14-16}$ and surfactant blend with concentration of $0.6 \% \mathrm{AOS}_{\mathrm{C} 14-16}+0.6 \% \mathrm{CA} 406 \mathrm{H}$ showed their stability with the maximum half-life time. Three surfactant blends without crude oil with the concentration of $0.2 \% \mathrm{AOS}_{\mathrm{C} 14-16}+0.2 \% \mathrm{TX} 100,0.6 \% \mathrm{AOS}_{\mathrm{C} 14-16}+0.6 \% \mathrm{CS} 460$ and $0.6 \% \mathrm{AOS}_{\mathrm{C} 14-16}+0.6 \% \mathrm{TX} 100$ showed their generated foam half-life with the same result of $50 \mathrm{~min}$. With the waxy oil, foam half-life time of two surfactant blends $0.6 \% \mathrm{AOS}_{\mathrm{C} 14-16}+0.6 \% \mathrm{TX} 100$ and $0.6 \% \mathrm{AOS}_{\mathrm{C} 14-16}+0.6 \% \mathrm{LMDO}$ noted as $15 \mathrm{~min}$ and $20 \mathrm{~min}$, respectively. The foam generated by surfactant IOS ${ }_{\mathrm{C} 15-18}$ resulted with the least stable foam without crude oil. Its halflife time was noted without crude oil as $25 \mathrm{~min}$ but with the both types of oil was noted same as $5 \mathrm{~min}$. The foam half-life time with crude oil was found less as compared to the foam half-life without crude oil. As discussed in the introduction of this paper, generated foam with the crude oil is destabilized. The tested surfactants confirmed that the generated foam weakens due to the mixing of oil phase.

\section{Liquid drainage}

Slow liquid drainage is favourable to maintain the stable foam. In the tested surfactants, the rate of foam drainage was dependent on viscosity of the liquid phase and foaming agent (surfactant) concentration. Figure 10 shows the $50 \%$ liquid drainage time after generated foam with formation water and both types of crude oil. Liquid drainage was observed with maximum time in the absence of waxy and normal oil by all tested individual and surfactant blends. Maximum time of 50\% liquid drainage was noted after generated foam with waxy and normal oil by the surfactant solution of $0.6 \% \mathrm{AOS}_{\mathrm{C} 14-16}+0.6 \% \mathrm{CA} 406 \mathrm{H}$, $0.6 \% \mathrm{AOS}_{\mathrm{C} 14-16}+0.6 \% \mathrm{TX} 100$ a nd $0.6 \% \mathrm{AOS}_{\mathrm{C} 14-16}+0.6 \% \mathrm{LMDO}$ as compared to the single surfactant $0.6 \% \mathrm{AOS}_{\mathrm{C} 14-16}$. Liquid becomes thinner due to liquid drainage caused by gravity and resulted gas bubble coalescence. The foam is less stable because of low liquid phase saturation. High viscosity liquid leads more stable foam.

Foaming properties of commercially available individual and blended surfactant solutions were investigated. The impact of surfactant concentration, surfactant type and crude oil type on the longevity of the generated foam were examined by measuring the volume of foam produced above the liquid level. The foam produced by the mixed surfactant solution was stable in the formation water but influenced by both types of crude oil. Half-life time of their generated foam with the both types of crude oil is smaller than that of half-life time of foam generated without crude oil. In the experiments, the foam behaviour of anionic surfactant $\mathrm{AOS}_{\mathrm{C} 14-16}$ with different concentrations is considered with formation water and oil types. Also, the anionic surfactant was combined with the non-ionic (TX100) and amphoteric surfactant (LMDO) to analyse the amount of foam produced with the both types of crude oil. The anionic surfactant $\mathrm{AOS}_{\mathrm{C} 14-16}$ showed good foamability with both types of crude oil when combined with the non-ionic (TX100) surfactant. The experimental results from these optimum surfactant solutions provide insights and guideline for surfactants in terms of foam stability with both types of crude oil.
Fig. 9 Half-life time of generated foam with formation water, and both types of crude oil

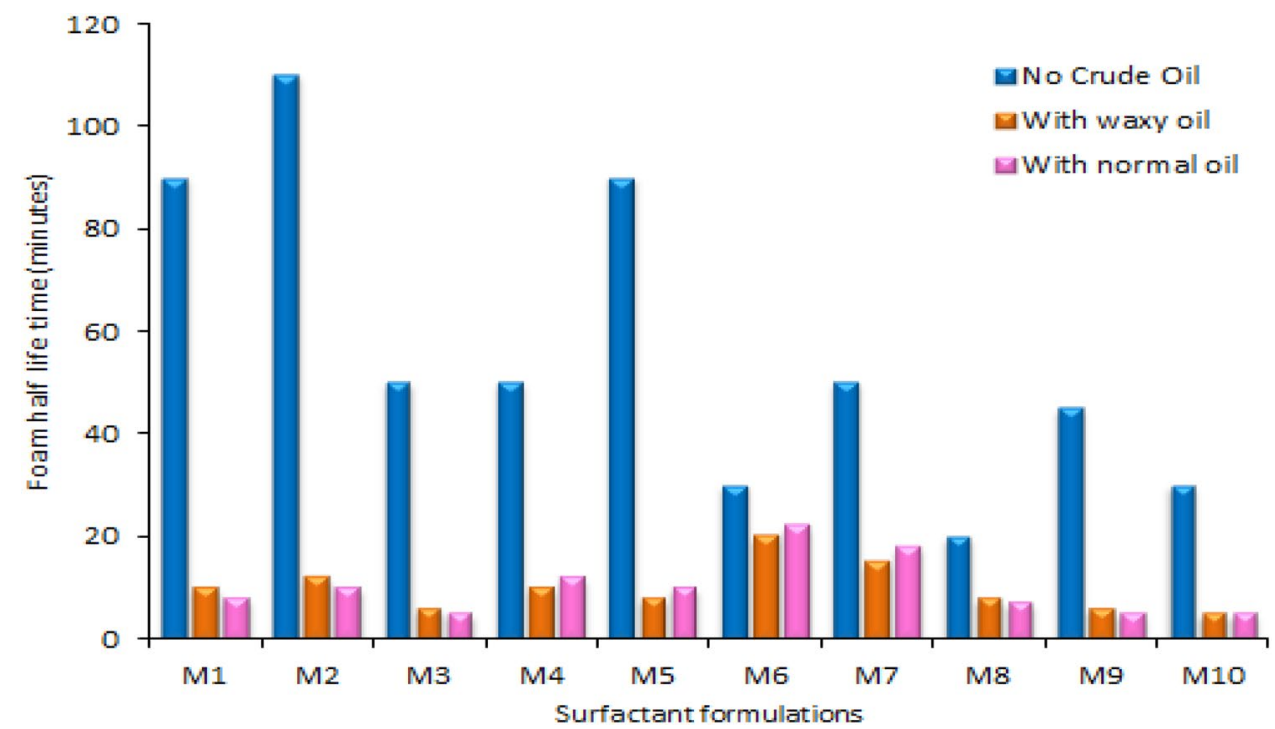


Fig. $1050 \%$ liquid drainage time with formation water and both types of crude oil

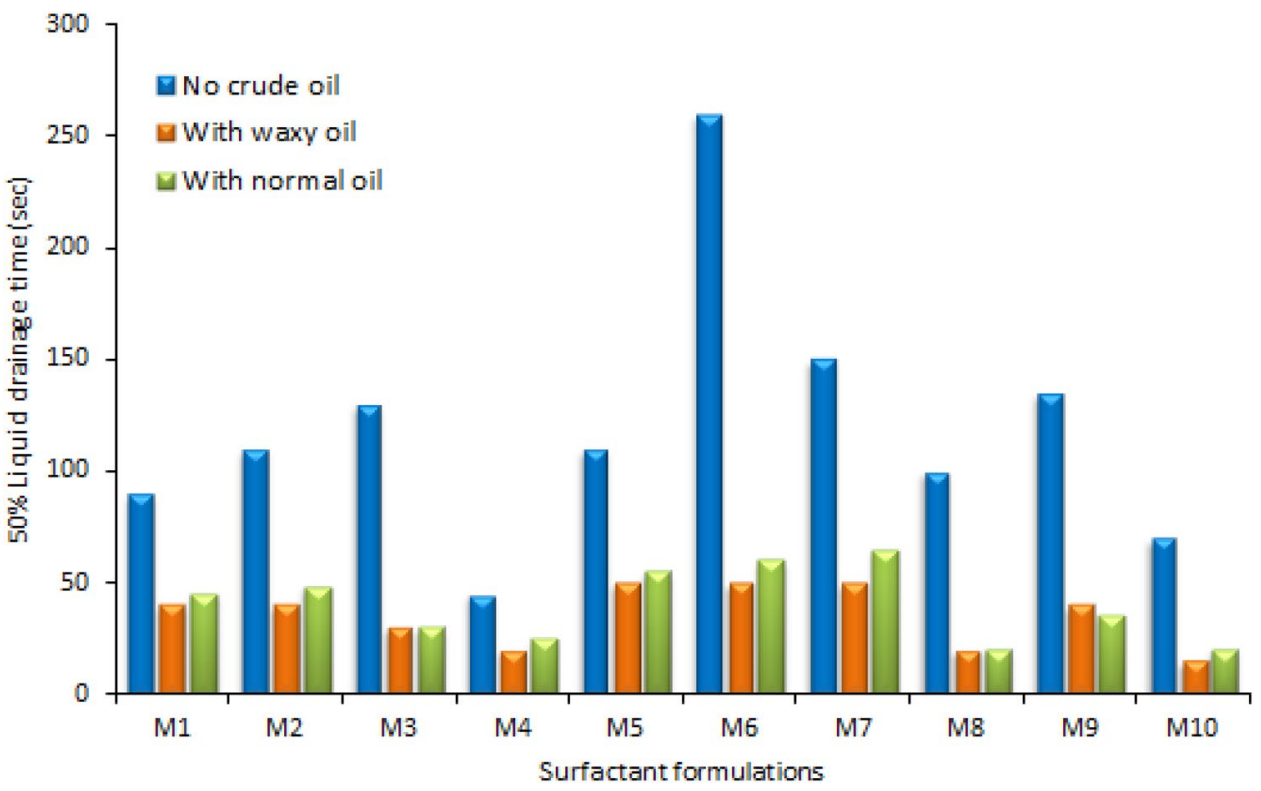

\section{Conclusions}

- All tested blended surfactants reduced IFT values between crude oil and formation water. Individual and blended surfactants were evaluated based on low IFT values for generating foam with formation water and two types of crude oil.

- The small volume of foam was generated with crude oil that reduces its foamability and half-life time of all tested surfactant solutions. The stability of generated foam with both types of crude oil was reduced due to the oil droplets accumulated on the plateau boundaries and lamellae.

- The stability of generated foam without crude oil was increased when increasing the concentration of single surfactant solution from $0.6 \% \mathrm{AOS}_{\mathrm{C} 14-16}$ to $1.2 \% \mathrm{AOS}_{\mathrm{C} 14-16}$. The same concentration of surfactant solution was noted with the small difference in the foam stability when tested with both types of crude oil.

- The maximum time was noted with the $50 \%$ liquid drainage and foam decay in the combined surfactant solution with concentration of $0.6 \% \mathrm{AOS}_{\mathrm{C} 14-16}+0.6 \% \mathrm{LMDO}$ and $0.6 \% \mathrm{AOS}_{\mathrm{C} 14-16}+0.6 \% \mathrm{TX} 100$ compared to the other surfactant solutions tested.

- The surfactant solution with concentration of $0.6 \% \mathrm{AOS}_{\mathrm{C} 14-16}, 1.2 \% \mathrm{AOS}_{\mathrm{C} 14-16}$, $0.6 \% \mathrm{AOS}_{\mathrm{C} 14-16}+0.6 \% \mathrm{LMDO}$ a nd $0.6 \% \mathrm{AOS}_{\mathrm{C} 14-16}+0.6 \% \mathrm{TX} 100$ with formation water and two types of crude oil showed the best resistance with maximum foam longevity.

\section{Future work}

Different techniques and mathematical/simulation models are used to measure the bubble size distribution. The transport characteristic of foam in microscopic scale mainly includes two aspects: one is the stable foam transported in the form of liquid lamellae, and the other is the unstable foam transported in the form of lamellae collapse and regeneration. Bubble sizes, as well as size distributions, play an important role in determining the final properties of the liquid/bubble mixture and must therefore be known with sufficient precision. To do this, a detail microscopic study is recommended.

Acknowledgements The authors would like to thank the Universiti Teknologi PETRONAS for supporting this research. Thanks also extended to SHELL Chemicals and STEPAN, USA for contributing the surfactant samples.

Funding We declare that, there is no any financial support to publish this paper.

Open Access This article is licensed under a Creative Commons Attribution 4.0 International License, which permits use, sharing, adaptation, distribution and reproduction in any medium or format, as long as you give appropriate credit to the original author(s) and the source, provide a link to the Creative Commons licence, and indicate if changes were made. The images or other third party material in this article are included in the article's Creative Commons licence, unless indicated otherwise in a credit line to the material. If material is not included in the article's Creative Commons licence and your intended use is not permitted by statutory regulation or exceeds the permitted use, you will need to obtain permission directly from the copyright holder. To view a copy of this licence, visit http://creativecommons.org/licenses/by/4.0/. 


\section{References}

Agneta M, Zhaomin L, Chao Z, Gerald G (2019) Investigating synergism and antagonism of binary mixed surfactants for foam efficiency optimization in high salinity. J Petrol Sci Eng 175:489-494

Andrianov A, Liu M, Rossen W (2011) Sweep efficiency in $\mathrm{CO}_{2}$ foam simulations with oil (SPE 142999). In: 73rd EAGE conference \& exhibition

Bisperink C, Ronteltap A, Prins A (1992) Bubble-size distributions in foams. Adv Coll Interface Sci 38:13-32

Duan X, Hou J, Cheng T, Li S, Ma Y (2014) Evaluation of oil-tolerant foam for enhanced oil recovery: Laboratory study of a system of oil-tolerant foaming agents. J Petrol Sci Eng 122:428-438

Exerowa D, Kruglyakov P (1998) Foam and foam films, ed. Elsevier, Amsterdam

Farzaneh SA, Sohrabi M (2015) Experimental investigation of $\mathrm{CO}_{2}$-foam stability improvement by alkaline in the presence of crude oil. Chem Eng Res Des 94:375-389

Guanhua N, Hongchao X, Shang L, Qian S, Dongmei H, Yanying C et al (2019) The effect of anionic surfactant (SDS) on pore-fracture evolution of acidified coal and its significance for coalbed methane extraction. Adv Powder Technol 30:940-951

Hargreaves AE, Hargreaves T (2003) Chemical formulation: an overview of surfactant-based preparations used in everyday life, vol 32. Royal Society of Chemistry

Harutyunyan LR, Harutyunyan RS (2019) Effect of amino acids on micellization and micellar parameters of anionic surfactant alpha olefin sulfonate $\mathrm{C}_{14}-\mathrm{C}_{16}$ in aqueous solutions: surface tension, conductometric, volumetric, and fluorescence studies. J Chem Eng Data 64:640-650

Huang B, Nan X, Fu C, Guo T (2021) Study of the bubble collapse mechanism and its influencing factors on stability under ultralow surface tension. Colloids Surf A Physicochem Eng Asp 618:126440

Kumar S, Mandal A (2017) Investigation on stabilization of $\mathrm{CO}_{2}$ foam by ionic and nonionic surfactants in presence of different additives for application in enhanced oil recovery. Appl Surf Sci 420:9-20

Lake LW (1989) Enhanced oil recovery. Prentice Hall

Llave FM, Olsen DK (1994) Use of mixed surfactants to generate foams for mobility control in chemical flooding. SPE Reserv Eng 9:125-132

Lopera Castro SH, Restrepo A, Ocampo A (2009) Use of divergent fluids as an alternative for enhanced recovery in naturally fractured cores. In: Latin American and Caribbean petroleum engineering conference

Machale J, Majumder SK, Ghosh P, Sen TK (2019) Development of a novel biosurfactant for enhanced oil recovery and its influence on the rheological properties of polymer. Fuel 257:116067

Machale J, Majumder SK, Ghosh P, Sen TK (2020) Role of chemical additives and their rheological properties in enhanced oil recovery. Rev Chem Eng 36:789-830
Manlowe DJ, Radke CJ (1990) A pore-level investigation of foam/oil interactions in porous media. SPE Reserv Eng 5:495-502

Memon MK, Elraies KA, Al-Mossawy MIA (2020) Performance of surfactant blend formulations for controlling gas mobility and foam propagation under reservoir conditions. J Petrol Explor Prod Technol 10:3961-3969

Nikolov A, Wasan D, Huang D, Edwards D (1986) The effect of oil on foam stability: mechanisms and implications for oil displacement by foam in porous media. In: SPE annual technical conference and exhibition

Osei-Bonsu K, Shokri N, Grassia P (2015) Foam stability in the presence and absence of hydrocarbons: From bubble-to bulk-scale. Colloids Surf, A 481:514-526

$\mathrm{Pu}$ W, Pang S, Wang C (2017) Experimental investigation of foam performance in the presence of crude oil. J Surfactants Deterg 20:1051-1059

Razavi S, Shahmardan M, Nazari M, Norouzi M (2020) Experimental study of the effects of surfactant material and hydrocarbon agent on foam stability with the approach of enhanced oil recovery. Colloids Surf A Physicochem Eng Asp 585:124047

Rosen MJ (2004) Surfactants and interfacial phenomena. Wiley

Schramm LL, Novosad JJ (1992) The destabilization of foams for improved oil recovery by crude oils: effect of the nature of the oil. J Petrol Sci Eng 7:77-90

Sheng J, Maini B, Hayes R, Tortike W (1997) Experimental study of foamy oil stability. J Can Petrol Technol 36

Sie C-Y, Nguyen QP (2020) A pore-scale experimental study of nonaqueous foam for improving hydrocarbon miscible flooding. J Petrol Sci Eng 195:107888

Solbakken J (2015) Experimental studies of $\mathrm{N}_{2}$ - and $\mathrm{CO}_{2}$-foam properties in relation to enhanced oil recovery applications

Stepan Company, Surfactants [online]. http://www.stepan.com

Tackie-Otoo BN, Mohammed MAA, Yekeen N, Negash BM (2020) Alternative chemical agents for alkalis, surfactants and polymers for enhanced oil recovery: research trend and prospects. J Petrol Sci Eng 187:106828

Weaire D, Hutzler S (1999) The physics of foams. Oxford University Press, New York

Wei P, Pu W, Sun L, Pu Y, Li D, Chen Y (2018) Role of water-soluble polymer on foam-injection process for enhancing oil recovery. $\mathrm{J}$ Ind Eng Chem 65:280-289

Yao X, Zhao G, Dai C, Wu Y, Lyu Y (2020) Interfacial characteristics and the stability mechanism of a dispersed particle gel (DPG) three-phase foam. J Mol Liquids 301:112425

Publisher's Note Springer Nature remains neutral with regard to jurisdictional claims in published maps and institutional affiliations. 